\title{
REVIEWS
}

Extinct and Vanishing Birds of the World. By James C. Greenway, Jr. American Committee for International Wild Life Protection, New York Zoological Park, New York 60, N.Y., U.S.A. $\$ 5$.

Readers will be surprised and shocked to learn that forty-four species and forty-three sub-species of birds have been exterminated during the 270 years since the dodo died. Nor does this include species, such as moas, known only by their bones, or those others-and they may be many-which have disappeared without ever having been named.

Most of the birds inhabited remote islands to which they presumably emigrated from distant continents and where, under specialized conditions and with no enemies, they developed into distinct forms. But eventually modern man appeared, often in a whaling ship, the forerunner of the floating factories now busy exterminating the great Order Cetacea. With man came rats : brown, which attacked ground-nesting birds, and black which destroyed the tree-nesters also. Against these predators, often reinforced by cats and pigs, to say nothing of monkey and mongoose, evolution had removed all defence.

After " extinct birds " comes "small populations". Seventyseven forms, species and sub-species in danger of extermination. Here indeed is ample scope for preservation. How very important it is that the few remaining unspoiled islands, Gough for instance, should remain truly inviolate.

Three-fifths of this 500 page book is given to accounts of these extinct and vanishing birds, clearly and attractively illustrated by D. M. Reid-Henry. One-fifth, with useful maps, is devoted to the geography of extinction, showing how it was that islands and the North American continent bore the brunt of "the sudden and devastating incursions of modern Europeans".

The general standard of this book is so high that small blemishes are a disappointment. The passenger pigeon is not given in the list of extinct species, though of course it is very fully dealt with in the text. Degrees of longitude are referred to as parallels on page 45 ; "off" instead of " of" spoils a sentence on page 104; a "not" is missed out on page 154 . But let not this deter the intending purchaser. This is a splendid book which will be of the utmost value both to the Fauna Preservation Society and to the Survival Service of the International Union for the Conservation of Nature. 
All who take a wide interest in preservation need this book. It is a companion volume to the Extinct and Vanishing Mammals of the Western Hemisphere, by G. M. Allen, and Extinct and Vanishing Mammals of the Old World, F. Harper. Allen's book is out of print, but Harper's may still be bought, price $\$ 4$, post free, from the American Committee for International Wild Life Protection. To avoid exchange difficulties, English orders should be given through booksellers.

\section{L. B.}

\section{Phoenix Re-born. By Maurice Burton. Hutchinson,} London. 25s.

It is not every day that we get a book that combines mythology with up-to-date zoological research and experiments, and, as very considerable make-weights, glimpses of the author's pets and some very worth-while observations on the behaviour of birds loosely known as "anting".

Maurice Burton has always had that first prerequisite so valuable to a real naturalist-an insatiable appetite for wanting to know " why". Without this laudable curiosity no naturalist is going to get much further than making lists of birds or plants or dragonflies and so on-which often do not get one anywhere in particular.

Burton's pet hobby is to debunk debunkers; and he often starts off with the object of discovering if there is not, after all, a grain of truth in some zoological fable. In this book he sets out to see what might be behind the ancient legend of the Phoenix; and it will seem fairly clear to the reader that he has gone a long way towards giving a reasonable explanation of what may have stimulated the imaginations of very early writers. The author has not merely done this, he has thrown much light on what may be the reason for other seemingly pointless pieces of behaviour among birds.

The book is clearly yet simply written with a refreshing minimum of the jargon so much beloved by some writers of animal behaviour.

Dr. Burton is to be congratulated not only on a very fascinating book; he is equally to be congratulated on having a young daughter whose graphic sketches and excellent photographs add much to the text. Seeing is said to be believing : this may not always be the case, but seeing photographs of what is described goes a very long way towards strengthening any writer's theories.

M. $\mathbf{K}$. 